\title{
RETÓRICAS DE LA TEATRALIDAD EN PLAUTO Y TERENCIO
}

\author{
BEATRIZ RABAZA, ALDO PRICCO, \\ DARIO MAIORANA Y LILIANA PEREZ \\ Universidad Nacional de Rosario
}

\begin{abstract}
Resumo: As diferenças entre a literatura dramática de Plauto e aquela de Terêncio tém sido tratadas, e resultam obvias muitas das referéncias dessa possivel dicotomia que se constrói partindo do traço comum do efeito cómico. No entanto, nesse trabalho intentamos dar conta das mencionadas divergências, de uma perspectiva de inserçáo com uma mesma prática: a Retórica. As duastteatralidades, baseadas em um mesmo programa retórico, caracterizam uma relaçáo entre ostentaçăo e evidéncia-recepçáo distinta e precisa: enquanto em Plauto os processos empáticos próprios do discurso dramático fazem impacto no corpo social e seu dinamismo, nos textos terencianos os mesmos processos tendem a postular uma poética particular, uma revalorizaçáo do trabalho do escritor (poeta).
\end{abstract}

Palavras-chave: Retórica teatral, Plauto, Terêncio, Público, Recepção, Discurso social, Poética.

Tradicionalmente se ha concebido la retórica como la práctica discursiva desarrollada en Grecia desde los sofistas y ligada en su mismo origen al poder y a las vias de acesso al mismo. Sabemos que este discurso sobre el lenguaje y sus efectos, adquirió status teórico a partir de la Retórica de Aristóteles, que fue romanizada por la produción de Cicerón (tanto por los Tratados que la tienen como objeto como por su praxis oratoria) y que se difundió en los primeros siglos de nuestra era y a lo largo de toda la Edad Media, por medio de los textos de Quintiliano. Sin embargo, al referirnos a la retórica de to teatral, lo hacemos conceptualizando a la Retórica como una práctica discursiva institucional que tiende a la persuasión, en tanto que alli está su finalidad, y por ella a una construccion significativa de lo "real", la construcción que el Orador, en tanto agente institucional diseñe. Es decir que como institución social, la Retórica determina aquello que es "real" y aquello que no lo es, lo que tienes sentido y lo que carece de sentido, constituyendo, entoces, un sistema de interpretación.

El Orador, en su dimensión discursiva, como entidad enunciadora, construye por medio de su práctica discursiva los Sujetos y los Objetos que enuncia, con intención de obtener la adhesión, el crédito, el consenso, la creencia que legitime su práctica y, en consecuencia, su discurso.

El Orador, en su dimensión social, conforme con las normas de la Institución, produce individuos que no sólo son capaces de reproducir estas normas, están obligados a ello.

Desde esta perspectiva hemos abordado el discurso dramático latino de los siglos III y II a.C., especfficamente en Plauto y en Terencio.

En tanto la materia de la imagen teatral resulta análoga a la materia del objeto-entidad social (comportamientos humanos), los processos de ligazón con el alocutario de la encunciación escénica se ven plagados de series tautológicas de signos: éstas, en su insistencia, en su presencia múltiple, intensificada y de coparticipación durante el transcurso del espectáculo, conducen a una presión, a una acumulación de tensiones slgnicas que conducen a su vez a resonancias empáticas. Si bien no podemos trazar una total correspondencia entre las máscaras de la piezas en cuestión y los seres físicos que se agrupam en esa hetarogeneidad que 
conforma el público, éste está en condiciones de adherirse, a través de personajes, de fábulas, a mitos y creencias de su ideologla cotidiana. Más, si las textualidades plautina y terenciana (en distinto grado) resultan atravesadas por discursos circulantes en la Sociedad Romana en que son producidas (por ejemplo el rol de la Matrona, que no se desprende del modelo helénico, tal como lo tratamos en trabajos anteriores 1 ), y se enmarcan en la circunstancia del juego polftico de la República. El espectador se identifica, se deja impresionar por una evidencia, aunque para ello requiera, paradojalmente, desmarcarse levemente de los héroes dramáticos: Servus, Senex, Adulescens, y otros, siempre "palliados".

Esta identificación constituye una de las operaciones más frecuentes de la "relación teatral", esa dinámica de intercambio en la que reside la incidencia de un discurso sobre la realidad.

Esta concepción cubre tanto las separaciones como las uniones, las rupturas y la continuidad: la dialéctica entre escenario y videncia/auditorio, el vínculo entre texto y representación, el intercambio (a reconstruir) entre espectador y actor, la comunicación entre actores y entre espectadores, como asf también las reglas que determinan la secuencia dramática, las presuposiciones de la enunciación escénica.

Este constructo, a expensas de sus mutantes y posibles constituyentes, implica que el objeto estudiado no puede ser abordado "en si mismo", ya que es la "otredad" lo que lo sostiene. Alteridad fundante que conduce a suponer la situación de enunciación como un modelo de simulación que permitirla reconstruir la "relación" e instancias espectaculares. Lo probable es que de uno $u$ otro modo se desarrollan procesos de ida y vuelta en los que el sistema escénico ejerce una "seducción", en términos de una atracción hacia el público basada primariamente, en la exposición de cuerpos (sujetos y objetos) humanos que reclaman una referencia aún antes de poner en juego una actividad intelectiva compleja: una serie de elementales percepciones que producen, por analogla, asociación u otras modalidades, "focos" de conducta cotidiana (o símiles) reconocida, sin los que el vínculo entre escenario y auditorio se vería debilitado.

Si la representación provoca por medio de la máscara la "emoción" de los espectadores, para que éstos confirmen en aquélla su propia conducta, es licito afirmar que los actores y su entorno semiótico forman el elemento activo (el retórico, el enunciante) y los espectadores el elemento reactivo). Cada espectador-lector se mantiene como sintesis de las experiencias pre-espectaculares que confrontan con lo que está ocurriendo en el escenario. Esta confrontación puede leerse como una colisión cuyos términos son: por un lado la experiencia ficticiainédita, y por el otro, la experiencia real-constituida. Confrontación que implica un "efecto" de irradiación del texto espectacular y também una receptividad del destinatario que se lo apropia, por lo que el sentido se constituye de un diâlogo intersubjetivo a partir del hecho de que el espectador (lector) es "sumergido" en pleno acontecimiento teatral para apelar a su facultad de "identificación" mediante procedimientos de simulación.

All, en la lectura, entra en funcionamiento la extensa serie de presupuestos culturales que rigen esa apropiación del discurso dramático por parte del público. Y sin pretender caer en el mito de la existencia de una manera universal y única de "recibir" la obra artística, es possibłe entrever y considerar ciertas constantes en el comportamiento estético e ideológico del receptor, de acuerdo con códigos (estéticos-ideológicos, también y asimismo, psicológicos) con los que éste está en condiciones de percibir y organizar el evento escénico.

Los discursos de las personae se proyectarlan - gracias e su experiencia imaginable - a modificar la experiencia real de los expectadores. De alff la operatoria retórica, la posibilidad de que entre "lo distinto" que provee el acontecimento dramático y el "statu quo" institucional, se

1. En un trabajo anterior: "Una ruptura del verosimil dramático en Plauto: la Matrona", publicado en la Revista de Letras N², Rosario, Public. U.N.R., 1990, intentamos demonstrar que em "un momento en que Roma mantiene su proyecto de expansion politica territorial, proyecto que se seguirá verificando en el transcurso de los siglos, el personaje de la Matrona se estructura como: a) espacio de ruptura del verosínil Comedia Nueva Griega; b) factor de solidificación de la familla, en el marco de la mos maiorum; c) la sintese de la sujeción a la autoridad del pater familias y al ideal de partriotismo - virtus - para la unidad ante la expansión. 
pantee un conflicto que implica, al mismo tiempo, el cotejo entre la ficción escénica y lo histórico-social. Todo esto atecta los modos de la convencion, habida cuenta de las "caracterizaciones" y "operaciones" que, respectivamente, "verosimilizan" y "artificializan" la propia convención. Acuerdos entre actores y público que establecen las condiciones indispensables para una comunicación: la Palliata procede as'́ a configurarse como un locus alejado (artificialización), pero al mismo tiempo quiebra su entorno para diseminar conductas latinizadas (verosimilización), en un desplazamiento que, en la redundancia de "citas" próximas a la práctica social de la recepción, se legitima en su mixtura.

Se conforma asl una "anagnórisis" como categorla desplazada hacia el público: reconhecimiento de un impedimento en la figura del servus en Plauto (tal como enunciáramos en nuestro trabajo sobre la servi facultas ${ }^{2}$ ); puede ocupar varios roles sociales, le es permitido, incluo, invertir su posición y su poder, pero sólo sucede como un corrimiento ficcional, pues al terminar la comedia todo vuelve a su sitio, el estatuto de jerarquias se restituye y corrobora.

En la práctica retórica plautina, la fabula y su posible didactismo no se recuperan en otra instancia, por ejemplo, si consideramos los versos 199 y ss. de Cistellaria:

AUXILIO Servate vostros socios, veteres et novos

augete auxilia vostris iustis legibus,

perdite perduellis, parite laudem et lauream, ut vobis victi Poeni poenas sufferat.

vemos cómo las virtudes que conforman la matriz conceptual de la mos maiorum, son evocadas sólo par legitimar las acciones bélicas contra Cartago. La coerción de un sistema axiológico se concreta alli, en la compleja serie de relaciones sociales, pero no está sujeta a procesos posteriores de estetización.

Sabemos que las experiencias de fiestas colectivas (al suspender los alcances de los cotidiano) instauran un fenómeno de autorregulación que "estetiza" la vida y resćata "lo real" de entre las redes del lenguaje elegido para esa celebración. Pero cuando del fenómeno de participación se pasa al de contemplación, es decir, al sistema dramático, la función reguladora se despleza a las modalidades espectaculares, al aparato enunciador escénico. La regulación social parece ser el destino de gran parte de la persuasión plautina, tal como podemos observar, por ejemplo, en los versos 68 y ss. de Captivi:

\section{PROLOGO Abeo. Valete, iudices instissimiz;}

domi, duellique duellatores optumi.

De este modo la construcción del público en la palliata plautina se plantea por omisión, por el solo hecho de compartir una convención, por participar del pacto de "confidencia" colectiva que solamente se verbaliza cuando las necessidades de la misma convención consciente (apartes, prólogos, entre otros) o del pacto (captatio) lo requierem. Este carácter de colectivi-

2. A pesar de la movilidad que se manifiesta en este personaje en cuanto a su comportamiento ficcional y más allá de que haga A pesar de la mollata los decires de las instltuciones representativas del poder en la Repúbllca Romana de los slglos ill y ll a.C., el servus en la obra de Plauto sólo instaura un poder flccional. cuvos If́mites auedan filados dor la duración de la Comedia. No suglere ningún tipo de movilidad social. Se trata de una servi facultas que se Instala en el espacio escénico por medio de procedimiento paródico. Parodia del discurso militar y senatorial, el discurso del servus no cuestlona nl censura más allá de lo que se cuestiona y se censura a partir del proplo procedimiento.

St el rol es prescripto por un amo desde el lugar del poder: la servi facultas resulta una simulación, porque ldeológicamente es el "destinatario" actancial la unidad abstracta que instituye el beneficio y permite la acción.

El servus en la palliata plautina: la servi facultas como flcción del espacio de poder. (en prensa) 
dad, de masividad implica la constitución de un público indiferenciado, con entidad grupal, pero no individual, con el protagonismo y el rol otorgados por ese pacto. Cuando emerge en el texto plautino una referencia más particularizada, la misma se enmarca en un alto grado de generalidad, tal como vemos, por ejemplo en los versos 5 y ss. de Poenulus, en donde se menciona al público que concurria a las representaciones: los ricos y los pobres (essurientes et saturi), las viejas prostituas (scortum obsoletum), los esclavos (servi), las nodrizas (nutrices), entre otros.

El público plautino tiene asignado, entonces, sólo el protagonismo de participar de los acuerdos que se establecen entre él y la escena: de reaccionar a la captatio inicial y al plaudite final, ambos, por otro lado, convencionales $y$, al mismo tiempo de compartir un sistema axiológico, el sistema de los pensable/decible.

Esta construcción permite evadir o suspender la reflexión sobre el objeto teatro, la metateatralidad, ya que focaliza exclusivamente la recepción de la simulación y, eventualmente, su plausibilidad, pero no el proceso, el aparato enunciativo, la práctica retórica. Este hecho se hace evidente en el tratamiento de los recursos de la fabula y de la relación entre ésta y el prólogo.

El mismo processo empático, en Terencio está orientado a un público cuyos atributos son diseñados por el discurso de sus prólogos. Tal como lo hemos abordado en nuestro trabajo: "La articulación de PROLOGO Y FABULA en el discurso dramático terenciano: el montaje espectacular de una polémica"3 en las obras terencianas los sucesos de la fabula se van desencadenando sin involucrar en una primera mirada, la función de llo personajes destinados a hacerla progresar. La dinámica que se establece entre enunciación escénica y recepción, determina una diferencia de comportamiento de sus máscaras respecto de la planteada en Plauto.

La caracteristica fundante es el desdoblamiento de textos dramáticos con jerarquias distintas: el reconocido como fabula, más extenso, y el prólogo, más intenso, más abarcador, que se proyecta más allá de los meros alcances introductorios que se le atribuyen.

Estes prólogos más que anunciar el drama siguiente, prepararlo, introducirlo como materia textual preponderante, se despojan de su oficio preliminar y habilitan al texto "de fábula" para que éste resulte no pieza fundamental, sino probatoria de un conjunto de juicios que requieren de una óptima recepción del texto dramático. Terencio, como máscara operante en sus prólogos, sostiene una controversia con sus detractores, a quienes instaura como personajes del drama de los prólogos. En este texto primordial se establece la ficcionalización de un agon fundamental, la polémica entre Terencio como máscara y sus adversarios. A partir de esta estrategia retórica, se diseña un programa poético que confiere entidad de público a aquél que es pensado e instituido por el lenguaje como público especializado, tal cơmo vemos en Hecyra 31 y ss:

PROLOGO: $\quad$ Eam calamitatem vestra intelligentia sedabit, si erit adiutrix nostrae industriae.

Es este público quien tiene carácter de juez de la produción dramática terenciana, el que puede legitimar su práctica como poética, como literaria si queremos, es decir, legitimar a Terencio como auctor frente a los demás escritores de la tradición literaria latina, utilizados como argumento de autoridad, ubicar al texto como lugar de lo "bello", lugar de lo especifico literario, e instituir a los poetae novi como los dramaturgos de lo nueve, de aquello que ocupa el lugar de lo que ya no puede seguir siendo. Vemos ambas cuestiones en:

3. En este trabajo nos referimos fundamentalmente al hecho de que el tratamiento que la tradición crftica ha INvado a cabo con los prólogos de las piezas terencianas ha obviado la función primordial de los mismos. Estos prólogos representan para nosotros la puesta en escena de un programa literario en tanto que la pieza probatoria de ese programa estarla constituida por la fábula. Se trata de un diálogo entre un poeta de lo nuevo (Terencio máscara) y la tradición que desea clausurar. La articulación de PROLOGO y FABULA en el discurso dramático terenciano: el montaje espectacular de una polémica". (en prensa) 
Adelphoe 4:

Eunuchus 29:

Heaut. 12:

Heaut. 28:

Heaut. 35: laudin an vitio duci factum oporteat.

In ita esse vos iam iudicare poteritis.

Vestrum iudicium fecit, me actorem dedit.

novarum qui spectandi faciun copiam

sine vitiis.

Adeste aeque animo; date potestatem mihi

statariam agere ut liceat per silentium,

ne semper servos currens, iratus senex,

edax parasitus, sycophanta autem impudens,

avarus leno asidue agendi sint seni

clamore summo, cum labore maxumo...

Vos eritis iudices

Date crescendi copiam

Si Plauto no ha dejado en forma declarada y expllcita una poética de lo dramático como entendemos que lo ha hecho Terencio, es evidente que su producción instauró una serie en la Literatura Dramática Latina muy diffcil de clausurar. El servus callidus, amando laboriosamente la textura dramática, el servus currens deslizándose veloz por los intersticios de la fábula, el senex airado a quien un ejército de esclavos pretende calmar en la Comedia, un parasitus voraz, espacio imantado que atrae en la escena todo, incluso la atención de un público disperso, itinerante. El público que Terencio piensa en silencio retenido en un lugar que le permita admirar una obra que desea stataria.

Terencio concibe otra forma de lo teatral, una estética de lo sutil, que sugiere que in hac est pura oratio, una dramaticidad que, sin agotarse en la acción, en el dinamismo de los personajes, se disemine por la superficie del lenguaje, dándole otro espesor. Una textura nueva, sine vitiis para aquellos que son capaces de esperar cosas nuevas.

Este público, con un doble gesto, legitimará un autor y una poética, clausurará una tradición instaurando lo nuevo y convirtiéndose en intermediario, en el paso intermedio para la persuasión final, la de la fabula. Primero se persuade acerca de la especificidad de lo dramático. Aceptada la seducción, quedan impuestas las normas que regirán la recepción de la fabula, que la prueba del programa. Todo este proceso retórico terenciano, que implica la dialéctica ostentación-recepción, intercambia y transacciona en el mercado de discursos; dicho en palabras de Angenot: participa del "arte de hacer lo nuevo con lo viejo" (Argenot, 1986).

Podemos concluir, entonces, que la retórica plautina es la retórica de la ilusión de movilidad social que se disuelve en el tempo de la Comedia. Terminada la fabula, este movimiento desaparece con los reaseguros que lo devullven a su lugar.

La retórica terenciana se constituye en el vehículo para poner en escena una controversia cuya resolución, conferida al público, determinará la validez de un programa literario y de una concepción de lo teatral que clausura la tradición, instaurándose como nuevo modelo.

\section{ABSTRACT}

The differences between Plautus's and Terence's dramatic literature have been already treated and many of the obvious references to such dichotomy, constructed from the common pattern of the comic effect, are obvious.

However, in this paper we try to account for the mentioned divergencies from a perspecve of insersion in a similar practice, namely rhertoric. Both theatricalities, based on the same rhetorical programme are characterized by a relation between ostentation and vision-perception different and precise: while in Plautus the empatic processes typical to the dramatic discourse hit the social body and its dynamism, in the Terentian texts, the same processes aim at postulating a particular poetics, a revaloration of the work of the writer (poet). 


\section{REFERẼNCIAS BIBLIOGRÁFICA}

ARGENOT, M. Intertextualidad y discurso social. Rosario, UNR, 1986.

BARBA, E. Anatomia del actor. Traduc. de Bruno Bert. México: Escenologla, 1988.

BEARE, H. La escena Romana. Traduc. de Eduardo Prieto. Buenos Aires: EUDEBA, 1972.

BENVENISTE, E. Le vocabulaire des institutions indo-européennes. Paris: Les Editions de Minuit, 1969.

BOAL, A. Teatro del oprimido. vol. II. Traduc. de Graciela Schminchuk. México: Nueva Visión, 1982.

BOBES NAVES, M. Semiología de la obra dramática. Madrid: Taurus, 1987.

DE TORO, F. Semiótica del teatro. Buenos Aires: Galerna, 1987.

DUCKHORTH, G. The nature of Roman Comedy. New Jersey: P.U.P., 1952.

DUPOND, F. L'acteur-roi. Le thêatre dans la Rome antique. Paris: Les Belles Letres, 1985.

EARL, D. Political terminology in Plauts. Historia, vol. 9, 1968.

ERAL, D. Terence and Roman politics. Historia, vol. II, 1962.

GUILLEMIN, A. Le public et la vie litteraire a Rome. REL, Paris, 1934.

HELBO, A. Teoría del espectáculo. Traduc. de Antonio Bonnano. Buenos Aires: Galerna, 1989.

INGARDEN, R. I JAUSS, H. Estética de la recepción. Traducc. de R. Sánchez Ortiz de Urbina. Madrid: Visor, 1989.

MARINIS, Marco de. Semiotica del Teatro. Milano: Bompiani, 1982.

PARATORE, E. II teatro di Plauto e di Terenzio. Roma: Ateneo, 1958.

PAVIS, P. Diccionario del Teatro. Traduc. de Fernando de Toro. Barcelona: Paidós, 1983.

PERNA, R. L'originalità di Plauto. Bari: L.D.V., 1955. 